\section{Studying golf putting in the laboratory}

\section{JOSEPH B. SIDOWSKI and TIMOTHY O'BRIEN* \\ University of South Florida, Tampa, Florida 33620}

Sidowski and O'Brien (1971) have presented data indicating that the perceptual-motor skills required in golf putting can be studied, to some extent, in the laboratory. The purpose of this note is to describe the apparatus used in these studies, the cost of which totaled approximately $\$ 35$, mostly odds and ends.

As all golfers know, the object of the game of golf is to knock a little white ball into a little round cup. No matter what distance he has to travel from tee to green (the cup is located on the green) and no matter what the hazards, the golfer at some time during the game must putt. The instrument used for this purpose is the putter. The putter, unlike the pursuit rotor stylus or the tracking joystick used in many studies of perceptual-motor skills in psychology, consists of a long shaft with a heavy end. Not all putters are alike, with the greatest variation being in the shape of the heavy end used to tap the ball.

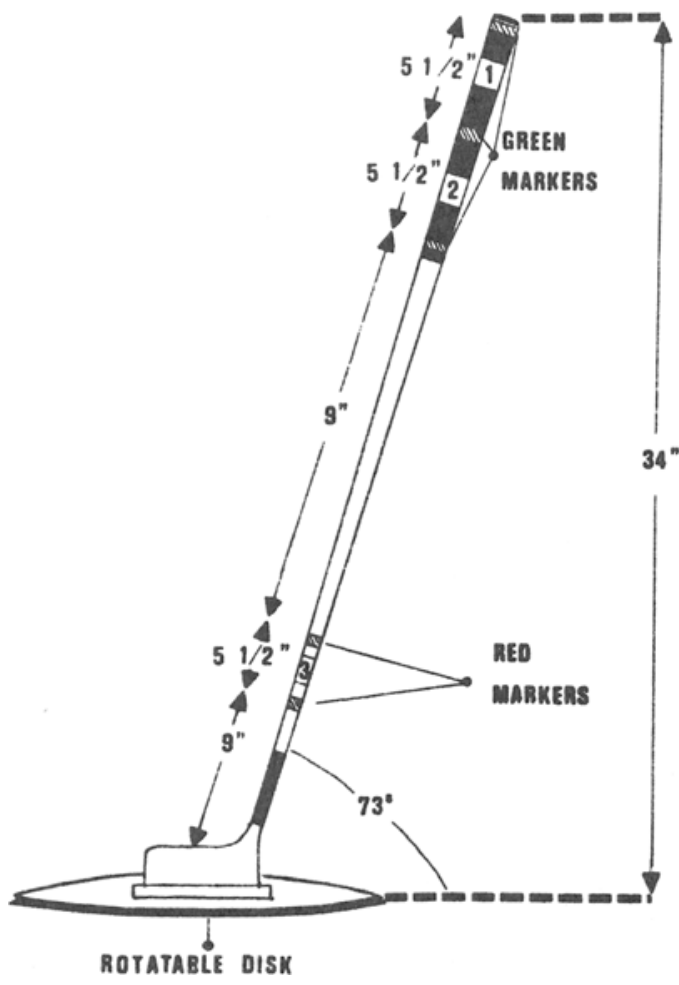

\section{MOUNTED BLADE PUTTER}

Fig. 1. Mounted blade putter.

*The authors wish to thank L. Evey for drawing Fig. 1.

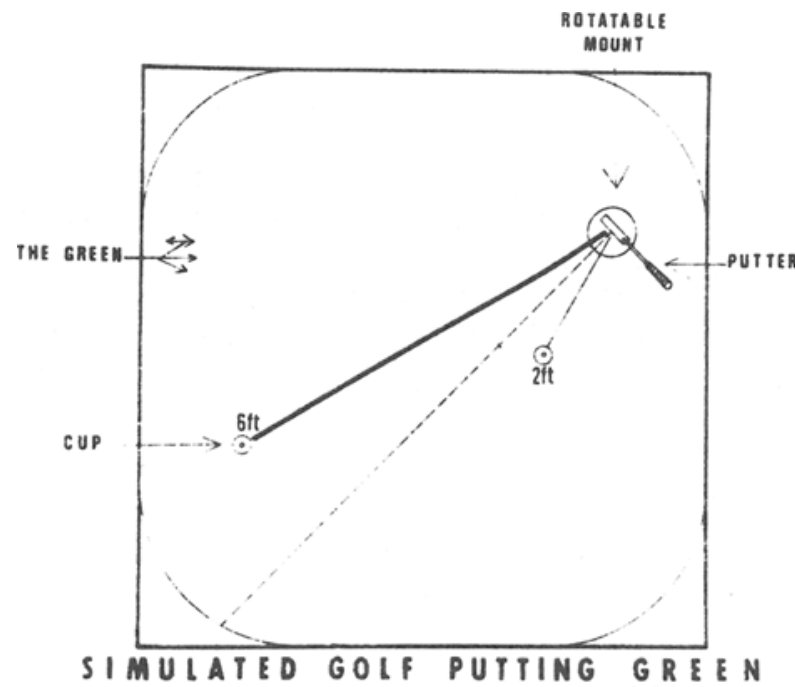

Fig. 2. Simulated golf putting green.

The commercial "blade" putter used in our research is shown in Fig. 1 and is typical of putters marketed today at prices ranging from approximately $\$ 3$ to $\$ 25$. In the figure, the number " 1 " at the top of the putter indicates the position for the left hand (right-handed S) and the number " 2 " shows the location for the right-hand grip. The red marker near the bottom (3) indicates a spot on the club grasped by the right hand when studying a particular putting technique, the Trevillion method.

For purposes of our research, the putter was permanently attached to a 10-in.-diam surplus record player turntable. A K\&E protractor of the same diameter was fastened to the turntable to measure the S's angular alignment accuracy. The turntable was flush-mounted on an $8 \mathrm{ft}$ long $\mathrm{x} 8 \mathrm{ft}$ wide $\mathrm{x} 4 \mathrm{in}$. high wooden platform covered with green indoor/outdoor carpeting. No part of the turntable or protractor was visible to $S$.

It is obviou's that this setup does not allow the $S$ to move the putter independently of the rotatable disk. The reason for this restriction is simple: our initial research interest centered on the S's ability to "line up" the shot. This alignment merely involves having the $S$ move the putter right or left until he believes that the center of the putter blade is in a position directly in line with the center of the cup. His angular error of alignment (left or right of the cup) is read off of the protractor by $\mathrm{E}$.

Circular "cups" (41/2-in. diam) were cut out of cardboard and painted, and the center pierced with a nail. This allowed for easy hand insertion of a cup at any location on the green.

Figure 2 shows the simulated golf putting green. The lines drawn at 6 and $2 \mathrm{ft}$, and the dotted line, are merely illustrative to show that the putter can be moved to align putts at various angles and distances. There are no lines on the laboratory green and, obviously, only one cup is 
on the green during the study of any experimental variable.

We have investigated a number of variables, including distance, the influence of cues, and feedback, and have found this inexpensive system very satisfactory for studying a motor skill practiced by over 12 million Americans on more than 10,000 golf courses.

\section{REFERENCES}

Sidowski, J. B., \& O'Brien, T. Golf putting: A laboratory investigation of "lining up the slot" variables. Paper presented at the 1971 meetings of the Psychonomic Society, St. Louis, Missouri.

(Received for publication November 17, 1972.) 